\title{
Para uma renovação teórico-metodológica da história: antigas propostas para uma nova história
}

\section{Towards a theoretical and methodological renewal of history: old proposals for a new history}

\author{
Claudio Umpierre Carlan \\ Professor da Universidade Federal do Estado do Rio de Janeiro \\ Av. Pasteur 458 \\ 22290-902 - Rio de Janeiro - RJ - Brasil \\ claudiocarlan@yahoo.com.
}

Keith Jenkins

\section{A HISTÓRIA} REPENSADA

Jenkins, Keith. A história repensada. Trad. Mario

Vilela; rev. técnica, Margareth Rago. São

Paulo: Contexto, 2001 $120 \mathrm{p}$. $\gamma_{\text {m }}$ al a função do historiador? Esta, de fato, não é questão nova, mas continua válida e pouco discutida. A partir de que instrumentos, teorias e métodos os historiadores selecionam seus temas de pesquisa e fontes documentais acerca do passado? Mas qual passado? De quem? Aquele dos ricos e poderosos ou o dos pobres e esquecidos? O de uma figura mítica e imaginária construída à imagem do branco europeu?

Recentemente, o historiador inglês especialista em história política Martin Bernal (2003) propôs a teoria do modelo antigo revisado. Segundo o autor, a civilização grega se teria originado dos povos afro-asiáticos e semitas, e não apenas daqueles de cultura indoeuropeia, como tradicionalmente defendido pelos pesquisadores ocidentais. De acordo com o modelo tradicional, recorrentemente ensinado, apenas os povos arianos e indo-europeus teriam 'cons-

truído' a civilização grega. Esse modelo de explicação estaria, segundo Bernal, em sintonia com o chamado modelo ariano, cujos racismo e tom imperialista estiveram relacionados às teorias científicas do século XIX. Afinal, como, aos olhos da elite culta ocidental, o berço da civilização europeia poderia ter sido influenciado por africanos e sírios?

Nessa mesma linha, tentando derrubar conceitos ou 'pré-conceitos' há muito enraizados, Keith Jenkins, professor adjunto de história na Universidade de Chichester, com passagem pela Universidade de Nottingham - ambas no Reino Unido -, onde lecionou história medieval e história moderna, questiona a visão positivista da história e acrescenta que a história não seria capaz de apreender plenamente a complexidade do passado. Em vez de procurar a verdade, os historiadores deveriam preocupar-se com as verdades acerca do passado (p.61). Sua tese, aliás, tem origem em trabalhos mais remotos dele próprio e de outros colegas, como sua tese de doutorado The postmodern history reader, em que já trabalhara com a relação entre política e ciência nas obras de Nietzche, Freud e Sorel.

A história repensada organiza com relativa precisão e didática as principais discussões que envolvem o debate histórico atual, sobretudo quanto à teoria e à filosofia da história. Também colabora para que "estudantes que estão começando a empreender o estudo da 
questão: o que é a história?" encontrem um porto seguro para a livre compreensão dos principais debates acerca de seu métier.

Na apresentação, Margareth Rago, responsável pela revisão técnica da obra, descreve como a história pode e deve ser repensada com ousadia, tanto por professores e pesquisadores quanto pelos alunos desde seus primeiros anos de formação. Muitas vezes nos concentramos na vida dos 'grandes homens', esquecendo do 'andar de baixo', da vida de homens infames, como aponta Michel Foucault e como nos lembra Rago.

A obra é dividida em quatro partes. Na Introdução, ao fazer uma revisão da literatura sobre o tema, o autor conduz o leitor a interessante e pertinente debate a respeito da temática central de sua obra: afinal, o que é história? Jenkins cita autores como Edward Carr (1989) e Geoffrey Elton (1969), teses e postulados teóricos importantes, ainda que, muitas vezes, datados. De acordo com Jenkins, as bases das ideias de Carr e Elton, apesar das revisões ocasionais, estariam eminentemente presas ao lastro dos anos 1960.

Segundo o historiador inglês, enquanto a filosofia e a literatura têm encarado mais seriamente a questão da natureza da história, pode-se considerar que a própria história, como campo disciplinar, ainda esteja 'atrasada' em termos teóricos, justamente por falta de investimento recente de vulto nesse campo. Sob tal prisma, A história repensada surgiu como continuação do livro de Carr, completando e adaptando o debate teórico para o século XXI. Jenkins realiza severas críticas ao fetichismo pela documentação ou à obsessão pelos fatos. Essa obsessão, ele observa, seria forte herança do século XIX, quando se supunha que "o documento falava por si". O autor chega mesmo a questionar o postulado "não existe história sem documentação escrita". Exagero ou não, ele considera que, preso a essa premissa, muitas vezes o historiador esqueceria as possibilidades do discurso teórico, abdicando assim de sua capacidade imaginativa, nos termos em que já nos falou seu colega inglês R.G. Collingwood.

No segundo capítulo está a pergunta que inquieta historiadores profissionais e demais estudiosos interessados: o que é história? Jenkins divide a questão em dois pontos principais: a teoria e a prática. No campo teórico ocorreriam ainda três divisões: a epistemologia, a metodologia e a ideologia. A ciência epistemológica se ligaria ao conhecimento que, segundo Jenkins, está presente em nossa sociedade atual e não em tempos pretéritos. Esse vínculo com o presente, contudo, não permitiria interpretações consensuais acerca do passado; ao contrário, a interpretação do passado é múltipla (um só passado, mas vários historiadores). Já no que concerne à metodologia, a história seria como um padrão em meio a uma série de discursos a respeito do mundo, e o conjunto de suas metodologias, algo mais prático, particular e de livre escolha do historiador, que o inseriria em uma historiografia cujas fronteiras seriam dadas, por sua vez, por sua escrita e seu modelo de interpretação. A metodologia, nesse caso, seria como uma ferramenta empregada para a análise das fontes selecionadas pelo pesquisador, que utilizaria, para analisar e identificar um determinado período histórico, meios dados por sua metodologia e sua seleção de fontes. Por fim, há a ideologia, da qual os intelectuais se apropriam para conferir sentidos e significados ao mundo a seu redor e alhures. De acordo com Jenkins, a história sempre servirá a um propósito político, seja colaborar com mais substância para as ideologias, seja legitimar atores e/ou instituições, funcionando assim como uma espécie de força legitimadora de 
um poder público ou uma doutrina social. O autor revela que desde os primeiros impérios, os governantes se preocuparam com os arquivos oficiais, narraram passagens de seu governo e conferiram sentido a sua existência e a da coletividade, a exemplo de Hamurábi, Ramsés II, Augusto, Constantino, Carlos Magno, Luís XIV, Napoleão - personagens históricos que revelaram grande preocupação com os fatos narrados em seus arquivos.

No terceiro capítulo, o autor identifica os principais padrões de perguntas e respostas que auxiliariam o trabalho do historiador. Uma dessas questões trata da 'verdade', cujo processo de construção passaria mais pela criação do que pela descoberta. Nesse sentido, Le Goff já defendia uma teoria que apontava para a inexistência de verdade absoluta na história. Tudo passaria, segundo o historiador francês, por uma tradição cultural dominante, fosse ela influenciada pelo platonismo, pelo cristianismo, pela razão e/ou pelas ciências (palavras-chaves na cultura ocidental). Não é à toa que Paul Joseph Goebbels, ministro da Propaganda do III Reich, em entrevista na década de 1930, já havia dito que "uma mentira contada cem vezes torna-se verdade". Nesse caso, o poder é que definiria o que é ou não verdade. Mas como seria a ação desse poder?

Em sua análise do poder, Michel Foucault (1979) identifica não a fonte dele, mas sim sua origem genealógica. Segundo o filósofo, essa origem determinaria os chamados micropoderes presentes nas sociedades modernas, os quais não se caracterizariam pela noção de classe nem se situariam unicamente nos campos da economia ou da política, estabelecendo-se antes em uma complexa rede de forças, presente em todos os aspectos da vida social. Chartier (1990) situou essa discussão em termos de signos do poder, uma série de monumentos, emblemas, medalhas, moedas, que identificariam o Estado com o objetivo de representar simbolicamente seu poder em vários campos.

Jenkins argumenta ainda que nenhum relato recupera inteiramente o passado, em parte porque o conteúdo dos acontecimentos pode ser ilimitado e a capacidade do historiador se resume sempre ao relato de pequenas frações do acontecido. Em sua visão, a história não consistiria unicamente num estudo do passado, mas sim num estudo da historiografia do passado, pois o pesquisador analisa e interpreta uma obra escrita em um determinado período histórico, e não o passado histórico de maneira geral.

Nessa discussão sobre o estudo do passado, o autor poderia ter chamado a atenção para o papel de outros tipos de documentação - não apenas os textuais - como fontes possíveis para a compreensão da história. Os historiadores contemporâneos, de maneira geral, utilizam diversas documentações para construir, ou reconstruir - como dizia Duby - esse passado. Estão disponíveis, atualmente, documentos iconográficos e arqueológicos que podem confirmar ou não a interpretação do historiador. Jenkins concentrou sua análise no textual, não mencionando as variadas fontes que encontramos no cotidiano. Algumas, aliás, já estão indicadas e suficientemente defendidas por sua importância em Combates pela história (1985), de Lucien Febvre, e, do historiador italiano Carlo Ginzburg, Mitos, emblemas e sinais: morfologia e história (1989), que também destaca a iconografia, aliada aos textos, como fundamental para a interpretação do passado.

No último capítulo do livro, Jenkins reúne todos os argumentos apresentados e define seu objetivo: "trazer alguma contribuição para que se desenvolvam alguns dos argumentos que giram em torno da questão 'o que é história'". O título do capítulo, "Construindo a 
história no mundo pós-moderno", é bem propício a esse debate, pois enfatiza a importância do passado em um mundo em radical transformação.

Por fim, eis a grande lição do livro de Jenkins: não se deve mesmo escrever acerca do passado a partir de uma posição ideológica predefinida (como o fizeram os nazistas alemães e os fascistas italianos da década de 1930). O discurso histórico, bem como outros, pode ser usado (mesmo involuntariamente) com fins políticos, auxiliando ou legitimando ideologias ou poderes constituídos (ou a se constituir) em determinada sociedade. Haveria, portanto, implicações éticas e políticas na escrita da história. Isso nos leva a concluir que o historiador deveria ser capaz - por meio do domínio das diferentes metodologias de seu campo e das ciências afins - de tornar-se suficientemente reflexivo a respeito da maneira de se fazer história no mundo atual.

Não se pode negar que muita coisa mudou desde a virada da Escola dos Annales de Marc Bloch e Lucien Febvre. De lá para cá, vários historiadores passaram a questionar mais a produção historiográfica, como Jacques Le Goff, Georges Duby, Le Roy Laudurie, Paul Vayne. A maior transformação, entretanto, talvez tenha sido provocada fora da história, como sugere Jenkins, ao apontar a obra do filósofo Michel Foucault como um momento de inflexão no campo historiográfico.

Muito se falou sobre as transformações ocorridas na história nos últimos trinta anos. É discutindo com autores como Hayden White, Geoffrey Elton e Edward Carr que Keith Jenkins, em Repensando a história - ao lado de What is history?: from Carr and Elton to Rorty and White, outro trabalho relevante do autor - torna-se leitura obrigatória nos recentes debates acerca do campo da teoria e da filosofia da história.

\section{REFERÊNCIAS}

CARR, Edward Hallet.

O que é história. 6 ed. Rio de Janeiro: Paz e Terra. 1989.

CHARTIER, Roger.

A história cultural: entre práticas e representações. Rio de Janeiro: Bertrand. 1990.

GINZBURG, Carlo.

Mitos, emblemas e sinais: morfologia e história. São Paulo: Companhia das Letras. 1989.
ELTON, Geoffrey.

The practice of history. London: Fontana, 1969.

FEBVRE, Lucien.

Combates pela história. 2. ed. Lisboa: Editorial Presença. 1985.

FOUCAULT, Michel.

Microfísica do poder. Rio de Janeiro: Graal. 1979. 